\title{
Anotações acerca da capacidade judiciária das câmaras municipais: Uma proposta de responsabilização da câmara por seus atos de gestão
}

\author{
Notes about the legal capacity of city councils: A proposal for the Board's accountability for \\ its acts of management
}

Igor Silva de Menezes ${ }^{1}$

\begin{abstract}
Resumo
Este trabalho apresenta uma discussão acerca da capacidade das Câmaras Municipais integrarem relação jurídica processual. O objetivo desse estudo é o de sintetizar os entendimentos doutrinários sobre o assunto. Igualmente, junto à jurisprudência dos tribunais superiores, descrever as hipóteses nas quais se reconhece capacidade processual à Edilidade. Utilizando-se de uma abordagem pragmática, a investigação apontou algumas situações específicas, com o intento de exemplificar, em casos recorrentes no cotidiano dos municípios, a relevância do tema, assim como as perplexidades das soluções apresentadas hodiernamente, revisitando-as e propondo novos paradigmas, conquanto seja necessária uma posterior e mais aprofundada reflexão acerca do assunto.
\end{abstract}

Palavras Chave: Capacidade, Judiciária, Câmara.

\section{Abstract}

This paper presents a discussion about the ability of municipalities to integrate procedural legal relationships. The aim of this study is to summarize the doctrinal understandings on the subject. Also, with the jurisprudence of the higher courts and describe the situations in which the Town Council recognizes procedural capacity. Using a pragmatic approach, this research pointed out some specific situations, with the intent to exemplify, in recurrent cases in the daily life of cities, the importance of the topic, and the perplexities of the solutions presented in our times, revisiting them and proposing new paradigms While it is necessary a further and deeper reflection on the subject.

Keywords: Capacity, Judicial, City Council.

1 Possui graduação em CIÊNCIAS JURÍDICAS E SOCIAIS APLICADAS pela Universidade Iguaçu (2006), na qual obteve o título de pós-graduado em DIREITO PÚBLICO. Atualmente é aluno efetivo do último ano do Mestrado em Direito da UNIVERSIDADE CÂNDIDO MENDES. Atua profissionalmente como PROCURADOR MUNICIPAL, ADVOGADO e professor de Deontologia Jurídica, Direito Administrativo e Tópicos de Direito Constitucional, em nível de graduação e pós-graduação, em Instituições do Rio de Janeiro. Contato: igormenezesadv@yahoo.com.br 


\section{Introdução}

O presente artigo teve como objeto de investigação a denominada "capacidade judiciária das câmaras municipais", e como escopo precípuo a descrição dos principais entendimentos doutrinários e jurisprudenciais sobre o assunto, para, ao final, propor uma reflexão crítica no que toca especificamente a responsabilização daquele Órgão quando no exercício atípico da função de gestão pública dos seus contratos, patrimônio, receita e pessoal.

Esse estudo se propõe a refletir sobre os contornos conferidos pela doutrina e jurisprudência em termos de capacidade jurídica processual de um Órgão Fundamental como a Câmara.

A complexidade do tema proposto ocupou inúmeros autores pátrios, dentre os quais se destacam Vitor Nunes Leal, no reverenciado artigo "Personalidade judiciária das Câmaras Municipais", e mais recentemente o professor José dos Santos Carvalho Filho, no trabalho intitulado "Personalidade Judiciária de Órgão Públicos".

O fato de carecer de personalidade jurídica repercute na questão processual, o que leva ao entendimento de que, apenas excepcionalmente, a Câmara poderá ser parte em juízo. Ater-se à personalidade jurídica, no entanto, subtrai do debate uma questão importantíssima: em sendo órgão destituído de personalidade jurídica, cabe responsabilização civil da Câmara Municipal? Eis a principal indagação, que aqui se propõe responder.

Em verdade, eleger como assunto o órgão Câmara Municipal se deve a necessidade de delimitação do tema na confecção de trabalhos acadêmicos. Ocorre que as discussões que aqui se pretende inaugurar podem refletir no tratamento jurídico processual de diversos órgãos que alcançaram constitucionalmente a prerrogativa de autonomia administrativa e financeira, eis que estas serão os principais fundamentos para a proposta de dilargamento da denominada capacidade judiciária. 


\section{Natureza jurídica das câmaras municipais}

No intuito de fornecer ao leitor um subsídio relevante acerca da estrutura do governo municipal, discorrer-se-á neste capítulo, sucintamente, sobre a estrutura desse ente da federação.

A Câmara dos Vereadores é um Órgão Público que integra o governo municipal. Esse governo, no âmbito dos municípios, é exercido por dois Poderes. Dessarte, juntamente com a Prefeitura, a quem cabe a função executiva, a Câmara exerce a função legislativa. É o que se extrai dos art. $2^{\circ}, 29$ e 31 da CRFB.

Seguindo o modelo tradicional da repartição das funções, os órgãos de um poder possuem funções típicas e atípicas. Esse sistema impede que um poder exerça função de outro, estabelecendo uma independência entre eles. A Prefeitura, nesse contexto, não pode, em regra, exercer atribuições de legislar, uma vez que essas são afetas constitucionalmente à Câmara, assim como à Câmara é vedado imiscuir-se na atividade específica de gestão do município, esta afeta à Prefeitura.

É cediço, no entanto, que o sistema de repartição de função não é exauriente, vale dizer, à função típica realizada pelo Legislativo incorporam-se funções atípicas.

A função típica da Câmara compreende, enquanto órgão legislativo municipal, a fazidura de leis de interesse local, bem como a fiscalização do Executivo, o que se depreende do art. $29, \mathrm{XI}$ e 31 da CRFB.

Ocorre que a Constituição Federal, a fim de prestigiar a independência entre os Poderes - o que se explica pelo princípio da simetria, eis que à Câmara dos Vereadores se estendem os princípios constitucionais que disciplinam o Poder Legislativo Federal -outorgou àquelas independência funcional, financeira e administrativa.

A inexistência de subordinação ou dependência entre os poderes que governam o município conferem ampla liberdade a estes dentro de sua esfera de atribuições. Não é outra a razão para dotar-se o Órgão legislativo municipal das referidas autonomias funcional, financeira e administrativa. Nessa ordem de idéias, além do exercício de sua função precípua de votar leis e fiscalizar, a Edilidade faz jus à parcela do orçamento do município, este pago em duodécimo, bem assim expede atos de administração interna de seu patrimônio, como os de administração do seu pessoal. É nesse aspecto que, doravante, cingir-se-á a discussão na qual se pretende contribuir com alguma inovação, eis que o consenso existente na doutrina não atende a alguns problemas que decorrem da prerrogativa predita. 
Ainda sobre a independência da Câmara face o Executivo, é mister esclarecer que ao falar-se de autonomia funcional, financeira e administrativa, quer se dizer que as Câmaras Municipais devem exercer suas atividades sem subordinação ao Executivo, que possuem orçamento próprio disciplinado na Lei de Responsabilidade Fiscal, e, por fim, que hes cabe a organização do seu quadro de servidores, o que resulta na possibilidade criação de cargos públicos, concessão de benefícios, contratação de pessoal e o mais.

Ressalte-se, por fim, que caracterizar a Câmara Municipal como Órgão, significa que, malgrado as prerrogativas aduzidas, esta não possui personalidade jurídica, ou seja, enquanto órgão, a Câmara integra uma pessoa jurídica, a saber: o Município. Isso assume relevo tanto na perquirição da possibilidade de responsabilização da Câmara, matéria afeta ao direito material, quanto na reflexão processual do tema proposto.

\section{Pressupostos processuais e a câmara em juízo}

Considerando que a possibilidade de responsabilização das Câmaras Municipais na Ordem Jurídica brasileira - quando estas estão realizando seu mister atípico de gestão - não pode depender da prestação voluntária dos seus administradores, forçoso revisitar a compreensão corrente que se tem desses Órgãos em juízo, vez que não se pode reconhecer que o perfil constitucional dessas entidades as tenha erigido ao status de sujeito de direitos e obrigações, sem conferir instrumentos jurídicos processuais para implemento dos mesmos. Daí a relevância da capacidade de ser parte, pressuposto processual de validade, para o incremento do debate proposto.

Como toda relação jurídica, a relação processual depende de requisitos para manifestar existência e validade. A Doutrina não é unânime na descrição dos pressupostos processuais, algo que deixaremos de abordar porque não interessa especificamente à solução da questão proposta. Tomamos por base a lição do processualista Alexandre Câmara para discorrer sobre o assunto.

Adiante, far-se-á uma síntese do que a doutrina moderna entende por pressupostos processuais, apenas para uma introdução do pressuposto efetivamente relevante ao debate. 


\section{Síntese dos pressupostos processuais e análise da capacidade de ser parte}

Para a finalidade desse estudo, partir-se-á do juízo de que os pressupostos processuais são: um órgão estatal investido de jurisdição, partes capazes, e uma demanda regularmente formulada.

A par da classificação dualista que se faz entre pressupostos processuais de existência e de validade, tem-se que:

Os pressupostos processuais de existência constituem-se como elementos necessários para que a relação processual possa se instaurar. Depende, pois, a existência de um processo, de um órgão estatal investido de jurisdição, partes e demanda. O exemplo mais distinto é um órgão investido de jurisdição, sem o qual sequer pode se falar em relação jurídica processual.

Os pressupostos processuais de validade, segundo Alexandre Freitas Câmara, "são os requisitos necessários ao desenvolvimento regular do processo".(CÂMARA: 2008, p. 233). Destarte, para se desenvolver validamente, imprescindível investidura do órgão na jurisdição, capacidade processual e regularidade formal da demanda.

O segundo que se nos interessa. A capacidade processual, integrante da tríade de pressupostos de validade, divide-se, igualmente, em três momentos, a saber: capacidade de ser parte, capacidade de estar em juízo e capacidade postularia.

A capacidade processual é a capacidade para estar em juízo, isto é, um verdadeiro consectário da capacidade de fato disciplinada pelo direito civil. A regra, nesse caso, dirigi-se precipuamente aos maiores de dezoito anos (art. $7^{\circ}$ do CPC). Os maiores de dezoito, então, poderão estar em juízo, ao passo que os menores púberes e impúberes deverão ser assistidos e representados respectivamente.

A capacidade postulatória é a que diz respeito à essencialidade do advogado à Administração da Justiça. Embora não o único, porque o membro do Ministério Público também a detém, aquele profissional é o grande titular dessa capacidade. Trata-se de uma exigência de representante habilitado tecnicamente para dirigir-se ao Estado Juiz.

A capacidade de ser parte é um instituto que, em regra, relaciona-se à personalidade jurídica. Isso porque 0 art. $7^{\circ}$ do Código de Processo Civil menciona que "Toda pessoa (grifo nosso) que se acha no exercício dos seus direitos tem capacidade para estar em juízo". Assim, a presunção corrente é a de que as pessoas físicas e as jurídicas cumprem o pressuposto em comento. 
Ocorre que a complexidade das relações jurídicas excepciona essa regra. Por esse motivo é que se formulou a categoria das pessoas formais. Essas são as universalidades patrimoniais desprovidas de personalidade jurídica, mas que possuem capacidade de direito, a exemplo da massa falida, do espólio, dos condomínios. A Lei Processual previu, no art. 12, a possibilidade dessas entidades despersonalizadas integrarem a relação jurídica processual ativa e passivamente.

Considerar órgãos detentores de autonomia administrativa e financeira, a exemplo das Câmaras, como pessoas formais, não nos parece nada teratológico, sobretudo porque, como se verá no capítulo oportuno, uma análise detida da Constituição Federal e da Lei de Responsabilidade fiscal pode conduzir a tal dedução.

Da dimensão reconhecida da capacidade judiciária da câmara

A jurisprudência reconhece, com tranqüilidade, a capacidade das Câmaras municipais serem parte. O STJ possui decisões que sintetizam o entendimento pretoriano:

RECURSO ESPECIAL № 1.109.840 - AL (2008/0283340-3)

RELATOR: MINISTRO BENEDITO GONÇALVES

RECORRENTE: FAZENDA NACIONAL

PROCURADOR: PROCURADORIA-GERAL DA FAZENDA NACIONAL E $\operatorname{OUTRO}(S)$

RECORRIDO: CÂMARA MUNICIPAL DE BARRA DE SÃO MIGUEL E OUTROS ADVOGADO: FELILPE REBELO DE LIMA E OUTRO(S)

EMENTA TRIBUTÁRIO. PROCESSUAL CIVIL. RECURSO ESPECIAL. MANDADO DE SEGURANÇA. CONTRIBUIÇÃO PREVIDENCIÁRIA INCIDENTE SOBRE SUBSÍDIOS DE AGENTES POLÍTICOS. ILEGITIMIDADE ATIVA AD CAUSAM DA CÂMARA MUNICIPAL. PRECEDENTES. RECURSO. ESPECIAL PROVIDO.

1. Cuida-se originariamente de mandado de segurança proposto pela Câmara Municipal de Barra de São Miguel/AL contra o INSS objetivando a declaração de inexigibilidade de contribuição previdenciária sobre os subsídios dos agentes políticos municipais.

2. Entendimento deste Tribunal de que as câmaras municipais possuem capacidade processual limitada à defesa de seus direitos institucionais, ou seja, aqueles vinculados à sua independência, autonomia e funcionamento. 
3. Por versar a presente demanda sobre a exigibilidade de contribuição previdenciária dos agentes políticos municipais, a Câmara recorrida é parte ilegítima ativa ad causam .

4. Nesse sentido, a linha de pensar de ambas as Turmas que compõem a Primeira Seção do STJ:

- A Câmara de Vereadores não possui personalidade jurídica, mas apenas personalidade judiciária, de modo que só pode demandar em juízo para defender os seus direitos institucionais, entendidos esses como sendo os relacionados ao funcionamento, autonomia e independência do órgão.

- Referido ente não detém legitimidade para integrar o pólo ativo de demanda em que se discute a exigibilidade de contribuições previdenciárias incidentes sobre a remuneração paga aos exercentes de mandato eletivo no Município. Precedentes.(REsp 730.979/AL, Rel. Min. Castro Meira, DJ de 2/9/2008).

- A despeito de sua capacidade processual para postular direito próprio (atos interna corporis) ou para defesa de suas prerrogativas, a Câmara de Vereadores não possui legitimidade para discutir em juízo a validade da cobrança de contribuições previdenciárias incidentes sobre a folha de pagamento dos exercentes de mandato eletivo, uma vez que desprovida de personalidade jurídica, cabendo ao Município figurar no pólo ativo da referida demanda (REsp 696.561/RN, Rel. Min. Luiz Fux, DJ de 24/10/2005).

5. Recurso especial provido.

O extrato colacionado sintetiza, portanto, o entendimento jurisprudencial majoritário no sentido de que, malgrado possuam capacidade para estar no processo capacidade a que denominam como capacidade judiciária -, restringem a mesma às seguintes hipóteses:

A primeira admite a capacidade de ser parte das Edilidades para defesa das suas prerrogativas institucionais, isto é, nas hipóteses de conflitos interorgânicos que consistem na subtração de um Órgão pelo outro de competências específicas outorgadas pelo legislador constitucional.

Como bem assevera Carvalho Filho:

"quando se cuida de órgãos subalternos, os eventuais conflitos que venham a surgir podem muito bem ser dirimidos pelos órgãos superiores. Se duas divisões de $m$ departamento administrativo assumem posições contraditórias, é o Diretor do Departamento que vai traçar a posição a ser obedecida. Esse fato é relevante e já o 
deixamos expressamente consignado para evitar indevida solução para esse de conflito". (2007, p. 6)

Ainda na mesma linha de raciocínio do insigne professor, por óbvio que o conflito de que tratamos cinge-se a Órgãos superiores que integrem a mesma pessoa jurídica. A Prefeitura e a Câmara, por exemplo. Nesse caso, não se pode admitir que a pessoa jurídica a qual os órgão estão vinculados integre a relação jurídica processual, uma vez que, a um só tempo, a pessoa seria autora e ré. Eis, então, a primeira hipótese autorizadora da relação processual entre órgãos.

Na segunda, há admissão de mais uma hipótese, esta mais remota, a de tutela de interesses do município em juízo pela Câmara Municipal. É exceção porquanto a regra é que o município seja representado em juízo pelo Prefeito ou Procurador, ao teor do art. 12, II da Código de Processo Civil. Mas quando este se queda inerte? A solução apresentada pelo STJ foi a de, novamente, reconhecer a capacidade judiciária da Câmara, veja-se:

Processo RMS 11499 / MG

RECURSO ORDINÁRIO EM MANDADO DE SEGURANÇA

2000/0003488-6

Relator(a)Ministro JOSÉ DELGADO (1105)

Órgão Julgador T1 - PRIMEIRA TURMA Data do Julgamento 01/03/2001

PROCESSUAL CIVIL. RECURSO ORDINÁRIO EM MANDADO DE SEGURANÇA. TRANSFERÊNCIA DE ESCOLAS DO ESTADO PARA O MUNICÍPIO SEM LEI AUTORIZATIVA. LEGITIMIDADE DA CÂMARA MUNICIPAL PARA IMPETRAÇÃO DO WRIT. PRECEDENTE.

1. Recurso Ordinário em Mandado de Segurança interposto contra decisão proferida pelo Egrégio Tribunal a quo que julgou a Câmara Municipal recorrente carecedora da ação no writ por ela impetrado contra a Resolução no 8.743/98, que autorizou a municipalização da Escola Estadual Américo Machado. Entendeu-se que a documentação acostada aos autos atestava que a autorização foi concedida pela

Secretaria Municipal, cujo titular não era o Prefeito Municipal, logo, o mandamus não poderia ter sido impetrado em seu desfavor.

2. Com efeito, não há como elidir o direito público subjetivo inerente à Câmara Municipal de defender os interesses locais, mormente quando a legislação 
exige expressamente a edição de lei autorizativa para a prática do ato impugnado, e esta não foi editada.

3. "O Município tem personalidade jurídica e a Câmara de Vereadores 'personalidade judiciária' (capacidade processual) para a defesa dos seus interesses e prerrogativas institucionais. Porém, afetados os direitos do Município e inerte o Executivo (Prefeito), no caso concreto, influindo fortemente os chamados direitosfunção (impondo deveres), existente causa concreta e atual, afetados os direitos do Município, manifesta-se o direito subjetivo público, seja ordinariamente ou supletiva extraordinária, legitimando-se ativamente "ad causam" a Câmara Municipal para impetrar segurança." (ROMS no 10339/PR, DJU de 01/08/2000, pág. 194, Relator Min. Milton Luiz Pereira)

4. Reconhecimento da legitimidade ativa ad causam da Câmara Municipal recorrente.

5. Recurso provido. Retorno dos autos ao Egrégio Tribunal de origem para que prossiga no exame do mérito da impetração.

A jurisprudência colacionada apóia-se no fato de que o ordenamento confere direitos e prerrogativas especificas a determinados órgãos, da mesma forma, não poderia prescindir de instrumento processual adequado para garantilos. É nesse sentido a lição de Vitor Nunes Leal, que asseverou "se o prefeito, por exemplo, viola esses direitos, não se pode conceber que não haja no ordenamento jurídico positivo do país um processo pelo qual a câmara dos vereadores possa reivindicar suas prerrogativas".

O problema é que reconhecer-se instrumento processual para garantir às Câmaras a defesa das suas prerrogativas institucionais e nega-lhe para cumprimento de obrigações decorrentes da sua independência, representaria, igualmente, um contra senso. ${ }^{2}$

Os que militam essa tese justificam que as Câmaras municipais são entes despatrimonializados, e que, em sendo o patrimônio da Câmara bem público municipal, o Município enquanto pessoa jurídica é que deveria integrar relação jurídica processual.

Há mais um fundamento prático que impõe a revisão do conceito de "despatrimonialidade" da Câmara. Ao se consagrar a irresponsabilidade do Órgão, conferindo a ele apenas a prerrogativa intangível de administrar o que the cabe, sem

\footnotetext{
2 Aparentemente, foi a mesma conclusão a que chegou STOCCO, pág. 9, conquanto o autor não reconheça a autonomia patrimonial da Câmara.
} 
reconhecer seu dever de arcar com os respectivos ônus, é ignorar o efeito pedagógico da responsabilização.

O argumento da despatrimonialidade do Órgão resta mais evidentemente inócuo quando diante de casos concretos. Ora, na hipótese de um acidente entre veículo de propriedade da Câmara com o de uma particular, o município que deverá responder? A Câmara não dispõe de orçamento próprio? A Câmara estará obrigada a subsidiar a defesa elaborada pelo órgão do outro poder?

Numa outra perspectiva - assaz recorrente, diga-se - se cogita: na hipótese do não recolhimento de verbas previdenciárias patronais ${ }^{3}$ devidas pela Câmara, as repercussões

3 AC-AgR-QO 1033 / DF - DISTRITO FEDERAL. QUESTÃO DE ORDEM NO AG.REG. NA AÇÃO CAUTELAR. Relator(a): Min. CELSO DE MELLO. Julgamento: 25/05/2006. Órgão Julgador: Tribunal Pleno Publicação: DJ 16-06-2006 PP-00004 EMENT VOL-02237-01 PP-00021. E M E N T A: CADASTRO ÚNICO DE CONVÊNIO (CAUC) - SECRETARIA DO TESOURO NACIONAL - INSTRUÇÃO NORMATIVA № 01/2005) - INCLUSÃO, NESSE CADASTRO FEDERAL, DE ENTIDADES ESTADUAIS DA ADMINISTRAÇÃO INDIRETA, POR EFEITO DE INADIMPLEMENTO OBRIGACIONAL EM QUE TERIAM ELAS INCIDIDO - CONSEQÜENTE IMPOSIÇÃO, AO ESTADO-MEMBRO, EM VIRTUDE DE ALEGADO DESCUMPRIMENTO, POR SEUS ENTES MENORES, DAS RESPECTIVAS OBRIGAÇÕES, DE LIMITAÇÕES DE ORDEM JURÍDICA, EM DECORRÊNCIA DA MERA VINCULAÇÃO ADMINISTRATIVA, A ELE, ENQUANTO ENTE POLÍTICO MAIOR, DAS EMPRESAS ESTATAIS INADIMPLENTES - NECESSÁRIA OBSERVÂNCIA DA GARANTIA CONSTITUCIONAL DO DEVIDO PROCESSO LEGAL COMO REQUISITO LEGITIMADOR DA INCLUSÃO, NO CAUC, DE QUALQUER ENTE ESTATAL OU DE ÓRGÃOS OU ENTIDADES A ELE VINCULADOS PRETENSÃO CAUTELAR FUNDADA NAS ALEGAÇÕES DE TRANSGRESSÃO À GARANTIA DO "DUE PROCESS OF LAW", DE OFENSA AO PRINCÍPIO DA INTRANSCENDÊNCIA DAS MEDIDAS RESTRITIVAS DE DIREITOS E DE DESRESPEITO AO POSTULADO DA RESERVA DE LEI FORMAL - MEDIDA CAUTELAR DEFERIDA - DECISÃO DO RELATOR REFERENDADA PELO PLENÁRIO DO SUPREMO TRIBUNAL FEDERAL. INSCRIÇÃO NO CADASTRO ÚNICO DE CONVÊNIO (CAUC) E ALEGAÇÃO DE OFENSA AO PRINCÍPIO DA INTRANSCENDÊNCIA DAS MEDIDAS RESTRITIVAS DE DIREITOS. - O postulado da intranscendência impede que sanções e restrições de ordem jurídica superem a dimensão estritamente pessoal do infrator. Em virtude desse princípio, as limitações jurídicas que derivam da inscrição, no CAUC, das autarquias, das empresas governamentais ou das entidades paraestatais não podem atingir os Estados-membros ou o Distrito Federal, projetando, sobre estes, conseqüências jurídicas desfavoráveis e gravosas, pois o inadimplemento obrigacional - por revelar-se unicamente imputável aos entes menores integrantes da administração descentralizada - só a estes pode afetar. - Os Estados-membros e o Distrito Federal, em conseqüência, não podem sofrer limitações em sua esfera jurídica motivadas pelo só fato de se acharem administrativamente vinculadas, a eles, as autarquias, as entidades paraestatais, as sociedades sujeitas a seu poder de controle e as empresas governamentais alegadamente inadimplentes e que, por tal motivo, hajam sido incluídas em cadastros federais (CAUC, SIAFI, CADIN, v.g.). LIMITAÇÃO DE DIREITOS E NECESSÁRIA OBSERVÂNCIA, PARA EFEITO DE SUA IMPOSIÇÃO, DA GARANTIA CONSTITUCIONAL DO DEVIDO PROCESSO LEGAL. - A imposição estatal de restrições de ordem jurídica, quer se concretize na esfera judicial, quer se realize no âmbito estritamente administrativo (como sucede com a inclusão de supostos devedores em cadastros públicos de inadimplentes), supõe, para legitimar-se constitucionalmente, o efetivo respeito, pelo Poder Público, da garantia indisponível do "due process of law", assegurada, pela Constituição da República (art. 50, LIV), à generalidade das pessoas, inclusive às próprias pessoas jurídicas de direito público, eis que o Estado, em tema de limitação ou supressão de direitos, não pode exercer a sua autoridade de maneira abusiva e arbitrária. Doutrina. Precedentes. A RESERVA DE LEI EM SENTIDO FORMAL QUALIFICA-SE COMO INSTRUMENTO CONSTITUCIONAL DE PRESERVAÇÃO DA INTEGRIDADE DE DIREITOS E GARANTIAS FUNDAMENTAIS. - O princípio da reserva de lei atua como expressiva limitação constitucional ao poder do Estado, cuja competência regulamentar, por tal razão, não se reveste de suficiente idoneidade jurídica que lhe permita restringir direitos ou criar obrigações. Nenhum ato regulamentar pode criar obrigações ou restringir direitos, sob pena de incidir em domínio constitucionalmente reservado ao âmbito de atuação material da lei em sentido formal. - $\mathrm{O}$ abuso de poder 
desse inadimplemento, tal como a inscrição em cadastros negativos que impedem a União celebre convênios com o Município, podem ser suportadas pelo órgão que constitucionalmente possui a incumbência de administrar a municipalidade? Esse fato não representaria uma subversão ao comando quantitativo de receita destinada ao funcionamento Órgão?

Adiante, fundamentos que conduzam a respostas negativas das indagações, de modo a se reconhecer o dever da Câmara de arcar com os ônus respectivos da prerrogativa de administrar.

\section{Da congênita relação entre a autonomia administrativa financeita da câmara e sua}

\section{capacidade judiciária}

A autonomia administrativa e financeira entre as Funções da República, e a convivência de ambas em apenas um ente moral, é que passaremos a analisar para fins de se perquirir da possibilidade de responsabilização da Câmara, enquanto Órgão independente, por seus atos de gestão.

Já foi dito nesse estudo que, em que pese o Município se configure juridicamente apenas numa persona, indubitável o reconhecimento da existência de dois entes despersonalizados dentro desta pessoa, mas com capacidade jurídica distinta, isto é, a possibilidade de adquirir direitos e contrair obrigações na ordem jurídica. Preciosa, nessa ordem de idéias, a lição de Hely Lopes Meirelles, que asseverou:

Embora despersonalizados, os órgãos mantêm relações funcionais entre si e com terceiros, das quais resultam efeitos jurídicos internos e externos, na forma legal ou regulamentar. $E$, a despeito de não terem personalidade jurídica, os órgãos podem ter prerrogativas funcionais próprias que, quando infringidas por outro órgão, admitem defesa até mesmo por mandado de segurança. (MEIRELLES, 2008)

Como visto, a doutrina publicista reconhece que os órgãos do Poder Legislativo

regulamentar, especialmente nos casos em que o Estado atua "contra legem" ou "praeter legem", não só expõe o ato transgressor ao controle jurisdicional, mas viabiliza, até mesmo, tal a gravidade desse comportamento governamental, o exercício, pelo Congresso Nacional, da competência extraordinária que Ihe confere o art. 49, inciso V, da Constituição da República e que lhe permite "sustar os atos normativos do Poder Executivo que exorbitem do poder regulamentar (...)". Doutrina. Precedentes (RE 318.873-AgR/SC, Rel. Min. CELSO DE MELLO, v.g.). Plausibilidade jurídica da impugnação à validade constitucional da Instrução Normativa STN no 01/2005. Decisão O Tribunal, à unanimidade, referendou a decisão de fls. 421 a 432, nos termos do voto do Relator. Ausentes, justificadamente, o Senhor Ministro Sepúlveda Pertence e, neste julgamento, o Senhor Ministro Eros Grau. Presidiu o julgamento a Senhora Ministra Ellen Gracie. Plenário, 25.05.2006. 
possuem apenas a capacidade judiciária. Tal capacidade sofre as restrições indicadas no capítulo anterior.

Passemos à análise da questão sob a ótica do Direito Financeiro, a fim de buscarmos eventual solução. A proposta de imbricar esse ramo do direito na discussão decorre da idéia aqui propugnada de que a Câmara pode ser responsabilizada por atos de gestão, haja vista que restará patente sua erição à condição de sujeito de direitos e obrigações.

O Texto Constitucional, no art. 168, ao dispor sobre o repasse das verbas do Executivo para o Legislativo, remete o intérprete à Lei complementar a que se refere o art. 165 §9o, do mesmo diploma, a saber, a Lei Complementar 101 de 2000, que dispõe:

Art. 168. Os recursos correspondentes às dotações orçamentárias, compreendidos os créditos suplementares e especiais, destinados aos órgãos dos Poderes Legislativo e Judiciário, do Ministério Público e da Defensoria Pública, ser-lhes-ão entregues até o dia 20 de cada mês, em duodécimos, na forma da lei complementar a que se refere o art. 165, § 9‥

Para melhor compreensão de como se dá, em termos legais, a responsabilização pelas despesas totais de pessoal em cada Ente Federado, e também em seus respectivos Órgãos com dotação orçamentária própria, mister a análise da Lei de Responsabilidade Fiscal, que regulamenta o artigo acima referido.

Há dualidade de obrigações entre a Casa Legislativa e a Executiva, malgrado ambas convivam em apenas uma pessoa jurídica. A problemática, por conseguinte, em se definir se as obrigações legais do Poder Legislativo Municipal pode, por carência de mecanismos processuais, transferir a responsabilidade pelas suas despesas com contratos, patrimônio e pessoal ao órgão gestor das contas municipais, o Executivo.

O artigo $19 \S 2$ 으 da LRF equaliza a questão da seguinte forma:

Art. 19. Para os fins do disposto no caput do art. 169 da Constituição, a despesa total com pessoal, em cada período de apuração e em cada ente da Federação, não poderá exceder os percentuais da receita corrente líquida, a seguir discriminados: $\S 2^{\circ}$ Observado o disposto no inciso IV do $\S 1^{1}$, as despesas com pessoal decorrentes de sentenças judiciais serão incluídas no limite do respectivo Poder ou órgão (grifo nosso) referido no art. 20. 
Aqui, tal como entre diversos outros dispositivos, a lei imputa a cada órgão [ou Poder], a responsabilização por suas despesas. Ademais, essa interpretação é intuitiva. Vale dizer, prescindiria de maiores digressões técnicas para chegar-se a tal conclusão.

Ora, se a constituição atribui ao legislativo autonomia financeira, essa decorrente da regra geral do art. 2 o da Constituição Federal, e da especial no art. 29- $A^{4}$, também da Constituição, como pode este gozar do benefício do poder de gestão de suas próprias contas, sem a respectiva responsabilidade de arcar com as obrigações dela decorrentes.

Ainda no art. 19 da Lei de Responsabilidade Fiscal colhemos que:

Art. 19. [...]

III - na esfera municipal:

a) 6\% (seis por cento) para o Legislativo, incluído o Tribunal de Contas do Município, quando houver;

b) $54 \%$ (cinqüenta e quatro por cento) para o Executivo.

$\S 1^{\circ}$ Nos Poderes Legislativo e Judiciário de cada esfera, os limites serão repartidos entre seus órgãos de forma proporcional à média das despesas com pessoal, em percentual da receita corrente líquida, verificadas nos três exercícios financeiros imediatamente anteriores ao da publicação desta Lei Complementar.

O texto referenciado, por isso, ratifica a evidente desvinculação das receitas e obrigações delas decorrentes da unidade de personalidade de cada Ente Federado. Ou seja, na seara do Direito Financeiro, poderíamos concluir que, para todos os efeitos, cada poder é equiparado a uma pessoa jurídica própria.

Destarte, levando-se em consideração que a Câmara Municipal tem autonomia administrativa e financeira (com dotação própria no Orçamento Municipal) cabe tão somente a ela realizar suas despesas, inclusive aquelas referentes as obrigações tributárias, como é o caso do recolhimento das contribuições previdenciárias. Vale dizer, à Câmara caberá suportar sua despesa total com pessoal - inclusive os encargos dela decorrentes, tal como contribuições sociais - à luz do que dispõe o art. 20, III, "a" da LC 101/2000 (Lei de Responsabilidade Fiscal).

Esse é o entendimento manifestado por diversos Tribunais de Contas Estaduais ${ }^{5}$ do

\footnotetext{
${ }^{4}$ CRFB, Art. 29-A. O total da despesa do Poder Legislativo Municipal, incluídos os subsídios dos Vereadores e excluídos os gastos com inativos, não poderá ultrapassar os seguintes percentuais, relativos ao somatório da receita tributária e das transferências previstas no $\S 5^{\circ}$ do art. 153 e nos arts. 158 e 159, efetivamente realizado no exercício anterior: (Incluído pela Emenda Constitucional no 25, de 2000).

5 A título de ilustração, veja-se a decisão do TCE do Matogrosso no proc. 18009/2008, que tratou contundentemente do assunto objeto de análise.
} 
país, no sentido de que, em virtude da eventual existência de débito previdenciário do Legislativo, é possível o desconto mensal pelo Poder Executivo, no repasse da Câmara Municipal, do valor correspondente a parcelas eventualmente acordadas junto ao INSS.

\section{Conclusões}

O presente artigo dedicou-se a compilar entendimentos doutrinários e jurisprudenciais acerca do que se entende por capacidade judiciária das Câmaras Municipais. Algumas são as conclusões a que chegamos:

Inicialmente, não se pode ignorar que a natureza jurídica das Câmaras Municipais interfere na compreensão e como esses órgãos podem integrar relações jurídicas processuais. Isso porque a regra do direito processual é que apenas entes com personalidade jurídica própria podem ser parte em processos judiciais. Destarte, enquanto órgão integrante do município, a Câmara deverá ter representação judicial por aquele.

A regra de atribuir-se capacidade processual a entes personalizados, no entanto, comporta exceções reconhecidamente admitidas e aplicadas pelos tribunais. O que se buscou questionar, contudo, foram as condições limitadas para a Edilidade integrar relações jurídicas processuais, sobretudo no que concerne a responsabilização desses entes, uma vez que são titulares de direitos autônomos em relação ao Órgão Executivo. Enquanto titulares de direitos, não seria racionalmente admissível que as Câmaras Municipais não fossem sujeitos de obrigações, e se, caso o fossem, não houvesse mecanismos jurídicos para se exigir seu cumprimento.

Assim, o mesmo fundamento que excepcionou a regra de relação jurídica processual deve ser aplicado para estender o entendimento atual sobre o tema. Vale dizer, se é com fulcro nas competências e prerrogativas independentes conferidas pela constituição que se reconhece a capacidade judiciária das Câmaras Municipais, da mesma forma essa capacidade deve atender a responsabilidade conseqüente dos atos praticados com base naqueles direitos.

Nesse diapasão, chega-se a conclusão que limitar a capacidade de ser parte das Câmaras Municipais às hipóteses de defesa institucional das suas prerrogativas ignora o atual tratamento constitucional conferido a esses órgãos, o que representaria, inclusive, 
subversão dos critérios constitucional e legalmente estabelecidos para a distribuição das receitas entre os Órgãos que gozam de autonomia orçamentária.

Em síntese, pode se dizer que, no exercício de sua função atípica de gestão do seu patrimônio e renda, precipuamente em questões contratuais, previdenciárias, de responsabilidade civil e relações de trabalho, deve ser reconhecida a capacidade das Câmaras Municipais em ser parte em processos judiciais com esses objetos - suportando os ônus respectivos, inclusive -, em prestígio a independência entre esses entes e o Executivo.

\section{Referências}

BRASIL. Constituição (1988). Constituição da República Federativa do Brasil: promulgada em 5 de outubro de 1988. 25. ed. São Paulo: Saraiva, 2010.

CARVALHO FILHO, José dos Santos. Personalidade judiciária dos Órgão Públicos. Revista Eletrônica de Direito do Estado (REDE), Salvador, Instituto Brasileiro de Direito Público, nำ1, julho/agosto/setembro, 2007, disponível em:

<http://www.direitodoestado.com.br/rede.aps>. Acesso em: 25 mai. 2010.

JUNIOR, Jenz Prochnow. A representação judicial do estado e seus desdobramentos. Disponível em: <http://www.pge.mt.gov.br/artigos/Artigo_13.pdf.>. Acesso em: 25 mai. 2010.

LEAL, Victor Nunes. Personalidade judiciária das câmaras municipais. Revista de Direito Administrativo, v.15, p. 46-64, jan./mar. 1949.

MEIRELLES, Hely Lopes. Direito Administrativo brasileiro. São Paulo: Malheiros, 2005.

MEIRELLES, Hely Lopes. Direito Municipal Brasileiro. 16.ed. São Paulo: Malheiros Editores, 2008.

PAULA, Ricardo Henrique Arruda de. A capacidade processual das Câmaras Municipais. Disponível em: <http//jus2.uol.com.br/doutrina/texto.asp?id=848>. Acesso em: 25 mai. 2010.

PEREIRA, Milton Luiz. Mandado de Segurança - Câmara de Vereadores - Personalidade Judiciária - Legitimação Ativa. Disponível em: <http://www.mundojuridico.adv.br>. Acesso em: 10 jun. 2010.

STOCCO, Rui. Natureza Jurídica das Câmaras Municipais. Disponível em:

<http://www.acamosc.org.br>. Acesso em: 25 mai. 2010. 
VIDAL, Márcio. Legitimidade de Agir e Capacidade Ativa e Passiva da Câmara Municipal e Assembléia Legislativa. Disponível em:

<http://www.mt.trf1.gov.br/judice/jud6/legitimidade.htm>. Acesso em: 10 jun. 2010. 